\title{
¿QUÉ VES CUANDO ME VES? \\ PERSPECTIVAS, ESCALAS \\ Y CONTEXTO EN LOS ESTUDIOS \\ DEL DERECHO ${ }^{1}$
}

\author{
LETICIA BARRERA
}

Leticia Barrera es Investigadora del CONICET con sede en el Instituto Superior de Estudios Sociales (ISES) de la Universidad Nacional de Tucumán. e-mail: leticiabarrera@yahoo.com

En estas líneas me propongo realizar un ejercicio de reflexión acerca de la investigación jurídica poniendo el foco en el modo en que, quienes procuramos indagar en los aspectos socioculturales del derecho, nos aproximamos a nuestro objeto de estudio y ejercitamos nuestra mirada afectando aquello que elegimos mirar. El trabajo se desarrolla sobre las consideraciones de algunas instancias de la investigación etnográfica que a mi juicio resultan significativas para la construcción de una conciencia acerca del derecho y sus condiciones de producción como un "saber situado», citando a Donna Haraway (1988).

En el desarrollo del trabajo, las reflexiones sobre el proceso de investigación se intercalan con algunas viñetas de la película Blow-Up de Michelangelo Antonioni $(1966)^{2}$ en una suerte de mapa de referencias cruzadas que contribuyen a reforzar

\footnotetext{
${ }^{1}$ El título está inspirado en el estribillo de una conocida canción del grupo de rock «Divididos». El uso del pronombre resulta sugerente dado el propósito de este trabajo de problematizar acerca de la mirada sobre los actores en las investigaciones en el campo del derecho. Mi agradecimiento a Claudio Martyniuk por su valiosa lectura de este trabajo, y a los evaluadores anónimos de Estudios Sociales por las sugerencias para la versión final. Salvo aclaración en contrario, las traducciones de los textos en inglés que se citan y/o transcriben son mías.

2 Film inspirado en el cuento de Julio Cortázar «Las babas del diablo». En España y América Latina se conoció como «Deseo de una mañana de verano». Dada la relevancia del significado del título en inglés para la elaboración de los argumentos presentados (en fotografía, blow-up es la ampliación de la imagen), prefiero dejar de lado su traducción al castellano y referirme a la película por su título en el idioma de origen.
} 
los argumentos presentados. Las imágenes de la película en las que se apoya este trabajo interpelan a la investigadora a volver la vista hacia sus propios medios y reflexionar sobre cómo en su campo de indagación -en el caso de la autora, el estudio de estructuras de la burocracia estatal como el poder judicial (Barrera, 2012)-, esos medios ${ }^{3}$ moldean la comprensión del objeto de estudio. Ahora bien, del mismo modo que las ampliaciones que realiza Thomas, el fotógrafo protagonista de Blow-up, cobran sentido en la secuencia de las fotografías tomadas en un contexto determinado, las reflexiones que aquí se presentan no responden a una elaboración en abstracto, producto del «encantamiento» de la autora con el método etnográfico, sino que son el producto de una investigación «contextualmente ubicada» (Muzzopappa y Villalta, 2011: 19); aun cuando dicho estudio no sea el foco de la presente discusión.

\section{EL RECORRIDO}

El viaje etnográfico y la experiencia que este conlleva se encuentran en los orígenes mismos de la antropología como disciplina, desde la que fue irradiándose como práctica del trabajo de campo hacia otras ciencias sociales bajo la influencia de la tradición antropológica británica y norteamericana que dominó el desarrollo de estas ciencias en el siglo XX (Guber, 2011). Espacio y temporalidad se conjugan en la construcción de un campo de investigación cuyos límites pueden resultar lábiles (Sarrabayrouse Oliveira, 2011).

Pero el viaje, como una práctica y como una metáfora, también ocupa un lugar de privilegio en la construcción del pensamiento jurídico contemporáneo aun cuando las condiciones de producción y transmisión de este saber no revistan interés analítico para la teoría del derecho, quedando en líneas generales reservado a la antropología o sociología jurídicas, o a bien a la historia de las ideas o la historia del derecho. Una excepción interesante resulta el ensayo de Diego López Medina «¿Por qué hablar de una ‘Teoría Impura del Derecho» para América Latina?» en el que este jurista colombiano procura dar cuenta de modo autorreflexivo de los diferentes marcos de significación que operan en los «sitios de producción» y en

\footnotetext{
${ }^{3}$ Más adelante, en el cuerpo del texto explico el sentido que le asigno a la palabra «medios» en una investigación.
} 
«sitios de recepción» (López Medina, 2009: 66-67) de la teoría general del derecho; concretamente del pensamiento de H. L. Hart, sobre el que López Medina construye su análisis. A partir de su trabajo con la obra de este filósofo en diferentes contextos académicos -en Colombia como nativo, y en la Universidad de Harvard, como un estudiante de doctorado oriundo de un país periférico (López Medina, 2009: 68)-, López Medina reflexiona sobre cómo en su recorrido una teoría originada en países con tradiciones propias en la producción académica va adquiriendo diferentes usos, matices, interpretaciones, según el contexto (en sentido amplio: social, cultural, político, económico, científico) de los actores que las producen, reciben, interpretan, y se apropian de ellas. Esa circulación de teorías jurídicas constituyen un campo transnacional dinámico (López Medina, 2009: 59), que estructura relaciones jerárquicas entre los actores locales y externos (Dezalay y Garth, 2002).

El énfasis de López Medina en ese ensayo (y en el proyecto académico más comprensivo del que aquel forma parte) está puesto en la necesidad del estudio de las transmutaciones que experimentan las teorías en su recorrido como un paso necesario para pensar («reconstruir») una teoría cultural del derecho en América Latina (López Medina, 2009: 90). El viaje que, como tantos otros académicos en el campo de las ciencias sociales, López Medina emprende desde la periferia hacia el centro de la producción científica (Dezalay y Garth, 2002), le permite tomar conciencia del contexto y perspectiva de su saber, al ingresar y participar de un modo diferente de educación y socialización en el derecho. Es el esfuerzo en detenerse a develar cómo en ese trayecto derecho y cultura resultan imbricados -sea que nominemos a esa relación «cultura jurídica» como lo hace este autor, «culturas de legalidad» (Couso, Huneeus y Seider, 2010), «conciencia jurídica» (Ewick y Silbey, 1998), «sensibilidad jurídica» (Geertz, 2000) o «subjetividad jurídica» (Brunnegger y Faulk, s/f)-, lo que contribuye, desde mi punto de vista, a una comprensión del saber jurídico y de su construcción como un saber situado en su contexto. No obstante el carácter reflexivo del recorrido que lleva adelante López Medina, en el que las distancias física y socio-cultural se vuelven reales, el trayecto que describe se desarrolla en una misma topografía: la del territorio reservado a los expertos. 


\section{PERSPECTIVAS}

Pensar el derecho más allá de las formas en que se manifiesta exige prestar atención no solamente al discurso, sino también a las prácticas, las relaciones, el comportamiento de los actores. Desde este lugar, no solamente emergen nuevos espacios susceptibles de indagación, sino que además las formas conocidas pueden adquirir nuevos significados. El derecho puede apreciarse como una relación de alteridad, sea que se lo estudie con categorías analíticas (conceptual y metodológicamente) tan disímiles como la teoría egológica del derecho de Carlos Cossio, o la teoría del campo jurídico de Pierre Bourdieu. No obstante, como disciplina, el derecho históricamente no se ha constituido para comprender a los otros, como sucede con la ciencia antropológica que no existe como tal sin un abordaje de la otredad (Grimson, Merenson y Noel, 2011). Aun a riesgo de generalizar, no es erróneo señalar que el jurista se aboca al conocimiento del otro desde afuera, desde una distancia normativa en la que su mirada está permeada por un juicio de valor sobre la conducta de los otros. En otras palabras, el «deber ser» que opaca la perspectiva de los actores: «No podemos de manera inmediata, sin un trabajo reflexivo, comprender perspectivas distantes a la nuestra» (Grimson, Merenson y Noel, 2011: 9).

La escena del final de Blow-Up evoca la «rotación de perspectiva» (Fernandes, 1975; citado en Grimson, Merenson y Noel, 2011) que impone metodológicamente el encuentro etnográfico en la búsqueda por comprender el punto de vista de los actores: dos mimos juegan un partido de tenis imaginario ante la mirada atenta de un grupo de pares y del protagonista, quien por un breve instante decide romper con su pasiva observación del juego, al recoger la pelota, también imaginaria, que había caído fuera del perímetro de la cancha y regresarla, a pedido de uno de los «jugadores». El partido se reanuda. Lo sabemos porque la cámara se detiene en el rostro del protagonista cuyos ojos siguen rítmicamente el trayecto de la pelota que segundos después escuchamos golpear en las raquetas de tenis imaginarias.

Al devolver la pelota al campo de juego, no sin antes haber vacilado, Thomas se vuelve también partícipe de la acción que realizan los personajes observados. Su propia mímica importa una inmersión, aunque breve, casi fugaz, en el terreno en el que se desenvuelven los actores dejando de lado su posición ajena y distante respecto de la escena de la que está siendo testigo. En el contexto de los estudios socio jurídicos, la fuerza simbólica de esta escena apela a la necesidad de separar temporariamente el «ser» del «deber ser» con un propósito de indagación; de modo similar al que demandaba 
uno de los nueve puntos de la propuesta programática de Karl Llewellyn (1930-31) para un enfoque realista del derecho. Dejar en suspenso posiciones normativas no implica, sin embargo, la renuncia de la investigadora a principios morales. El campo de la investigación etnográfica suele estar atravesado por dilemas éticos y políticos en la relación con los actores, más aún cuando sus sistemas de creencias, valores y prácticas entran en conflicto con los de la investigadora. La conciencia y el manejo de esas relaciones dicotómicas forman parte del proceso de reflexión y análisis de la investigación. Sobre este punto volveré hacia el final del trabajo.

Luego de reanudado el juego, la larga toma del final de la película muestra al fotógrafo vagando por el césped del parque mientras su figura va alejándose de la cámara. Repentinamente, su imagen es borrada de la escena para dar lugar a los títulos del final que se proyectan en letras opacas, de color negro sobre el mismo césped por el que segundos antes caminaba el protagonista, recordando así a la espectadora que «él también es sólo una imagen en un trozo de film» (Peavler, 1979: 889) y que «la ilusión ha terminado» (Peavler, 1979: 890). Esto ha dado lugar a diferentes lecturas: la renuncia del protagonista (y la del director) a la búsqueda de referentes (Marcus, 2009: 229); es decir la ausencia de la «verdad» material que corrobore el enigmático crimen que con su cámara había captado (¿o acaso construido?) en aquel parque. O bien se trata de reconocer las limitaciones de su medio para desplazarse más allá del alcance de su lente (Fernández, 1968-1969: 30, citado en Peavler, 1979: 889 $)^{4}$. Esto último resulta muy significativo porque el modo en el que el protagonista percibe y experimenta la realidad está mediado por la lente de su cámara. Esta relación define su punto de vista 5 .

\footnotetext{
4 «...la realidad es para Thomas lo que encuentra a través de la lente de su cámara; cuando ve el cuerpo que yace en el parque no la lleva consigo; y cuando vuelve al lugar para tomar una foto, no solamente el cuerpo no está allí sino que no hay rastro ni evidencia de que haya existido alguna vez. La única ampliación que no le había sido robada es tan difusa y abstracta que probablemente tendría menos valor probatorio que uno de los cuadros de Bill (con los que Patricia la ha comparado)» (Peavler, 1979: 889).

${ }^{5}$ La invisibilidad es precisamente una cualidad fenomenológica del medio, como también una táctica de poder y autoridad (Hull, 2012: 13). Eisenlorh señala que «hay una tendencia del medio a desparecer en el acto de mediación. De hecho, los medios solamente pueden funcionar como tales si en el acto de comunicar algo son capaces también de alejar la atención de su propia materialidad y tecnicismo para redirigirla hacia aquello que está siendo mediado» (Eisenlorh, 2011: 14, citado en Hull, 2012: 13).
} 
Como señala Francis en su análisis de la película (1985), más que documentar la realidad $^{6}$, el fotógrafo es capaz de crear una ilusión de modo similar al que lo hace un escritor ${ }^{7}$. La cámara, sin embargo, no es el autor en sí, no tiene agencia propia, sino que provee el marco - a veces inadecuado- a aquello que el fotógrafo/autor decide enmarcar. En la elección consciente del marco (¿qué es lo que se incluye?, ¿qué se deja afuera?) el fotógrafo crea una realidad ilusoria cuya validez no es ni menor ni mayor que la de otra mirada. La cámara, instrumento óptico moderno de verificación factual, puede ser entonces otro dispositivo para ficcionalizar la realidad. Para Francis, ese es precisamente el eje temático de la película, y no la resolución del enigma alrededor del homicidio (Francis, 1985: 48).

Así como la cámara provee al fotógrafo un modo único, distintivo de capturar el mundo, la investigadora se enfrenta a la indagación desde su perspectiva teórica, sus métodos, su posición en la academia, su comunidad, sus habitus disciplinarios y su «epistemocentrismo» (Bourdieu y Wacquant, 2008), situaciones que pueden predefinir su campo de estudio (Guber, 2011: 46-7). Ahora bien, si la investigadora, con su bagaje teórico y de sentido común, va colocando los mojones de su campo de estudio, «el sentido último del campo», como dice Guber, «está dado por la reflexividad de los nativos», aun en el supuesto que aquella perteneciera al mismo grupo o sector que los sujetos de su estudio, ya que sus intereses como investigadora difieren de los intereses prácticos de aquellos. El desafío está, continúa esta autora, en transitar de la reflexividad propia a la de los nativos (Guber, 2011: 47); posibilidad dada por el trabajo de campo que le permite a la investigadora confrontar las propias categorías con otros marcos de referencia con los que necesariamente se compara (Guber, 2011: 50), y, de este modo, trascender su percepción y conocimiento directo del mundo. La legitimidad del conocimiento que proviene de «estar allí», en el campo, requiere en ese tránsito, una «vigilancia epistemológica» por parte de la investigadora para evitar desarrollar un punto de vista «encantado» de las categorías y lógicas que organizan el mundo social de los actores (Vecchioli, 2013: 10). Tampoco descartarlas de antemano, como podría ocurrir en una etapa pre-reflexiva.

${ }^{6}$ Thomas aspira a retratar el realismo social del Londres de su época, aquel que late lejos del aburrimiento y tedio cotidianos de su oficio como prestigioso fotógrafo de la moda.

${ }^{7}$ El paralelo es interesante porque, como sabemos, la película se basa en un relato de ficción. 


\section{ESCALAS}

La película también pone el foco en el proceso de selección y organización del material que ha sido acopiado (Peavler, 1979); o, en los términos de las artes visuales, en el trabajo de edición o montaje que permite con posterioridad el armado de la historia que se quiere contar. «La edición, entonces, es el instrumento privilegiado del conocimiento ex post facto -el dispositivo por el que una comprensión retrospectiva se manifiesta en sí misma en forma cinemática» (Marcus, 2009: 227). Una vez reveladas, las fotografías tomadas por el protagonista en el parque parecen dar a conocer un hecho no anticipado, ajeno a su atención mientras disparaba la cámara. El conocimiento de ese hecho va revelándose por capas, en las distintas escalas de las ampliaciones que el fotógrafo va realizando casi compulsivamente. Según Marcus en la secuencia de la película en que este personaje revela aquellas imágenes, las exhibe, observa, amplía, y reinicia ese proceso, aquel carece del conocimiento a posteriori sobre lo acontecido que hace posible editar (montar) una historia (Marcus, 2009: 228). A los ojos de este autor, lo que llama poderosamente la atención de esta secuencia es que Antonioni logra invertir radicalmente la relación entre conocimiento y edición, de modo tal que es el proceso en sí lo que lleva al protagonista a descifrar el significado que subyace en las imágenes que ha tomado. El trabajo de edición y montaje emerge entonces como un modo de conocimiento, permitiéndole al fotógrafo perforar la superficie de los acontecimientos retratados para discernir aquello que bajo la apariencia de un encuentro amoroso parece ser en realidad una trampa para un asesinato (Marcus, 2009: 228).

El trabajo de investigación etnográfica también tiene una naturaleza procesual y cambiante; se trata de una "focalización progresiva» (Hammersley y Atkinson, 1994: 191), en la que el conocimiento -como en la acción de revelado, observación y ampliación que Thomas realiza de sus imágenes- va construyéndose en la reflexión acerca del análisis, de la información obtenida y del diseño de la investigación, etapas que se encuentran íntimamente relacionadas. Durante este proceso van tomando forma los problemas planteados al comienzo de la investigación, surgen nuevos interrogantes, se descartan otros, las acciones adquieren nuevos significados. «El campo se clarifica y delimita» (Hammersley y Atkinson, 1994, 192). No obstante, Hammersley y Atkinson señalan, siguiendo a Lacey, como un mal común del trabajo de campo el afán del investigador o investigadora de documentar todo lo que ocurre en él; su necesidad de querer estar en todos 
los lugares y de permanecer en el campo el máximo tiempo posible. Esta suerte de apego naturalista «a decir las cosas tal cual son", sostienen, deja poco espacio para la reflexión teórica, subestimando el proceso de análisis que resulta implícito o no suficientemente elaborado (Hammersley y Atkinson, 1994). Sobre ese tipo de ansiedad dan cuenta también Schleker y Hirsh cuando sostienen que el giro hacia la investigación etnográfica en los estudios culturales y de medios (MCS, Media and Cultural Studies) y en los estudios de la ciencia y la tecnología (STS, Science and Technology Studies), resultó en una crisis de contexto en estas disciplinas. Si bien el incremento en el uso del método etnográfico en varios campos, entre ellos los estudios de derecho y sociedad (Barrera, 2010), se debió a la necesidad de investigadores e investigadoras de contextualizar las prácticas de sus sujetos de estudio en sus ámbitos cotidianos, el resultado, al menos en los MCS y STS, fue el intento de lograr aun una mayor contextualización.

«Se hizo visible más que nunca que cualquier perspectiva era simplemente una perspectiva acerca de otra perspectiva, o una relación a su vez en relación con otra. Los debates causaron una gran incertidumbre epistemológica acerca de la esencia de los individuos y las cosas con anterioridad a cualquier perspectiva o contextualización sobre ellos; es decir, antes de cualquier intento de otorgarles un sentido» (Schleker y Hirsh, 2001:71).

Según los autores, la necesidad de documentar todo lo que ocurre en la realidad de los actores, vuelve difuso el campo, resintiendo la consistencia de la reflexión y el análisis. Lo mismo ocurre con las ampliaciones que realiza el protagonista en su afán desesperado por descifrar aquello que a sus ojos todavía permanece oculto. ¿Se trata acaso de un rostro?; ¿el cañón de una pistola?; ¿un cuerpo? No podemos saberlo con certeza. Cada vez que la escala de la ampliación aumenta, la imagen gana en dimensión pero pierde en definición. De ese modo, el objeto de escrutinio yace impreciso bajo la trama de gruesos puntos expandidos en la que se ha convertido la imagen captada por la cámara (Kozloff, 1967:29).

En uno de sus breves comentarios sobre la película, Antonioni afirmaba que el film estaba cuestionando «la naturaleza de la realidad» (Antonioni, citado Peavler, 1979: 892). Al poner el foco en la exploración que el fotógrafo hace de su medio -sus ampliaciones en una escala cada vez mayor-somos testigos de la expansión de los límites de la realidad). El artista descubre, o inventa, una dimensión que resulta 
bastante cuestionable en términos de realidad, o de verdad (Antonioni, citado Peavler, 1979: 891 y 893). A la inversa, en el caso de la investigación etnográfica, el foco puesto en lo particular, en lo micro (lo universal de lo particular), sirve como un instrumento de interpelación a otras ciencias sociales en sus generalizaciones y empleo de categorías etnocéntricas para dar cuenta de la «verdad» de la acción humana. Como señala Guber, «una etnografía es, en primer lugar, un argumento acerca de un grupo humano»(Guber, 2011: 130) ${ }^{8}$. Una conclusión interpretativa a la luz de los casos estudiados, y no una verdad totalizadora de la acción humana (Ídem. 18-19).

\section{DUPLICIDAD}

El estudio empírico de ámbitos estructurados burocráticamente como el poder judicial presenta una particularidad que le es inherente a su objeto de estudio: resulta difícil fijar la mirada en algo que dificultosamente resulte estático. Y con esto no me refiero al ritmo o eficiencia de los procedimientos burocráticos, sino, más bien, al punto de vista desde donde se abordan las instituciones. Cuando el foco está puesto en las políticas y prácticas cotidianas de la burocracia, es muy probable que éstas se presenten como cuerpos racionales y eficientes, por ejemplo en el relato de los actores acerca de sus quehaceres, o en la descripción de las rutinas guionadas que indican su accionar (Hoag, 2011: 81-2). Al mismo tiempo, para la observadora externa (y también quizás para la mirada crítica de algunos nativos), aquellos cuerpos resultan opacos, inescrutables y carentes de racionalidad (Hoag, 2011). Esta doble perspectiva, señala Hoag, implica el riesgo de anteponer al análisis nuestros ideales acerca del funcionamiento de la burocracia. Para decirlo de otro modo, aquellos ideales tienden a estructurar el análisis a través de categorías binarias que buscan explicar cómo las burocracias deberían funcionar contrariamente a como lo hacen en la práctica. Para evitar este riesgo, o al menos intentar ejercer un control epistemológico de nuestro análisis, sostiene este autor, es necesario avanzar o dejar de lado esa relación binaria que lo precede (Hoag, 2011: 84). Para ello, propone apelar a la reflexión de Haraway mencionada al inicio acerca de la conciencia del saber, esto es, entender los saberes

${ }^{8}$ El destacado me pertenece. 
como prácticas situadas. Esta concepción de la producción de saber como una práctica que se corporiza en la mirada de la investigadora, nos permite recordar que todas las miradas vienen de alguna parte; resultando un conocimiento parcial. Esto último, advierte Hoag siguiendo nuevamente a Haraway, no implica abogar por un perspectivismo, sino poner en entredicho la idea de una mirada universal y todopoderosa para examinar la acción social.

\section{Referencias bibliográficas}

BARRERA, LETICIA (2010): «Derecho y Sociedad: Historia, crisis y nuevas perspectivas», en: Revista Argentina de Teoría Jurídica, Buenos Aires, Universidad Torcuato Di Tella, vol. 11, № 2. BARRERA, LETICIA (2012): La Corte Suprema en escena. Una etnografía del mundo judicial, Buenos Aires, Siglo XXI Editores

BOURDIEU, PIERREY WACQUANT, LOIC (2008): Invitación a una sociología reflexiva, Buenos Aires, Siglo XXI Editores.

BRUNNEGGER, SANDRA Y FAULK, KAREN (S/F): «Introduction. Making Sense of Justice», en: Sandra Brunnegger y Karen Faulk (comps.), Senses of Justice in Latin America.

COUSO, JAVIER, HUNEEUS, ALEXANDRA Y SEIDER, RACHEL (2010): Cultures of Legality. Judicialization and Political Activism in Latin America. Cambridge, Cambridge University Press.

DEZALAY, YVES Y GARTH, BRYANT (2002): The Internationalization of Palace Wars. Lawyers, Economists and the Contest to Transform Latin American States, Chicago, The University of Chicago Press. EWICK, PATRICIA Y SILBEY, SUSAN S. (1998): The Common Place of Law. Stories from Everyday Life, Chicago, The University of Chicago Press.
FRANCIS, RICHARD LEE (1985): «Trascending Metaphor: Antonioni's Blow-Up», en: Literature/Film Quarterly, vol. 13, № 1.

GEERTZ, CLIFFORD (2000): Local knowledge, further Essays in Interpretive Anthropology, Nueva York, Basic Books.

GRIMSON, ALEJANDRO, MERENSON, SILVINA Y NOEL, GABRIEL (2011): «Descentramientos teóricos. Introducción», en: Alejandro Grimson, Silvina Merenson y Gabriel Noel (comps.), Antropología ahora. Debates sobre la alteridad, Buenos Aires, Siglo XXI Editores.

GUBER, ROSANA (2011): La etnografía: método, campo y reflexividad, Buenos Aires, Siglo XXI Editores. HAMMERSLEY, MARTYN Y ATKINSON, PAUL (1994): Etnografía. Métodos de investigación, Barcelona, Paidós.

HARAWAY, DONNA (1988): «Situated Knowledges: The Science Question in Feminism and the Privilege of Partial Perspective», en: Feminist Studies, vol. $14, \mathrm{~N}^{\circ} 3$.

HOAG, COLLIN (2011): «Assembling Partial Perspectives: Thoughts on the Anthropology of Bureaucracy», en: PoLAR: The Political and Legal Anthropology Review, vol. 34, № 1. 
HULL, MATHEW S (2012): Government of Paper. The Materiality of Bureaucracy in Urban Pakistan, Berkeley y Los Ángeles, University of California Press. KOZLOFF, MAX (1967): «The Blow-Up by Michelangelo Antonioni», en: Film Quarterly, vol. 20, №3. LLEWELLYN, KARL N. (1930-1931): «Some Realism about Realism. Responding to Dean Pound», en: Harvard Law Review, № 44.

LÓPEZ MEDINA, DIEG0 E. (2009): «¿Por qué hablar de una ‘Teoría Impura del Derechos para América Latina?», en: Daniel Bonilla Maldonado (ed.), Teoría del derecho y trasplantes jurídicos, Bogotá, Siglo del Hombre Editores, Universidad de los Andes, Pontificia Universidad Javeriana.

MARCUS, MILLICENT (2009): «Freccerò on Blow-Up: Toward a Macro-Vision of Italian Film», MLN, vol. $124, N^{\circ} 5$.

\section{Registro bibliográfico}

BARRERA, LETICIA

«¿Qué ves cuando me ves? Perspectivas, escalas y contexto en los estudios del derecho», en: ESTUDIOS SOCIALES, revista universitaria semestral, año XXV, n 48, Santa Fe, Argentina, Universidad Nacional del Litoral, primer semestre de 2015, pp. 135-145.
MUZZOPAPPA, EVA Y VILLALTA, CARLA (2011): «LOS documentos como campo. Reflexiones teóricometodológicas sobre un enfoque etnográfico de archivos y documentos estatales», en: Revista Colombiana de Antropología, vol. 47, № 1.

PEAVLER, TERRY J. (1979): «Blow-Up: A Reconsideration of Antonioni's Infidelity to Cortázar», PMLA, vol. 94, No 5.

SCHLEKER, MARCUS Y HIRSH ERIC (2001): «Incomplete Knowledge: Ethnography and the Crisis of Context in Studies of Media, Science and Technology», en: History of the Human Sciences, vol. 14, № 1. VECCHIOLI, VIRGINIA (2013): "Las victimas del terrorismo de Estado y la gestión del pasado reciente en la Argentina», en: Papeles del CEIC, vol. $13, \mathrm{~N}^{\circ} 1$.

Recibido: 18 / 12 / 2014

Aprobado: 15 / 02 / 2015 
